\title{
The Influence of Catalysts on Biofuel Life Cycle Analysis (LCA)
}

Pahola Thathiana Benavides ${ }^{a}$, Donald C. Cronauer ${ }^{a}$, Felix Adom ${ }^{a}$, Zhichao Wang ${ }^{b}$, Jennifer B. Dunn ${ }^{a^{*}}$

a Systems Assessment Group, Energy Systems Division, Argonne National Laboratory, 9700 S. Cass Avenue, Argonne, IL 60439, United states

${ }^{b}$ Eco Engineers. 300 E Locust Street, Des Moines, IA, 50309, United states

${ }^{*}$ Corresponding Author

Phone Number: 01-630-252-9984

Fax Number: 01-630-252-3443

Email Address:

${ }^{*}$ jdunn@anl.gov 


\begin{abstract}
Catalysts play an important role in biofuel production but are rarely included in biofuel life cycle analysis (LCA). In this work, we estimate the cradle-to-gate energy consumption and greenhouse gas (GHG) emissions of $\mathrm{Pt} / \mathrm{V}-\mathrm{Al}_{2} \mathrm{O}_{3}, \mathrm{CoMo} / \mathrm{\gamma}-\mathrm{Al}_{2} \mathrm{O}_{3}$, and $\mathrm{ZSM}-5$, catalysts that could be used in processes to convert biomass to biofuels. We also consider the potential impacts of catalyst recovery and recycling. Integrating the energy and environmental impacts of $\mathrm{CoMo} / \mathrm{Y}-\mathrm{Al}_{2} \mathrm{O}_{3}$ and $\mathrm{ZSM}-5$ into an LCA of renewable gasoline produced via in-situ and ex-situ fast pyrolysis of a blended woody feedstock revealed that the ZSM-5, with cradle-to-gate $\mathrm{GHG}$ emissions of $7.7 \mathrm{~kg} \mathrm{CO}{ }_{2} \mathrm{e} / \mathrm{kg}$, could influence net life-cycle GHG emissions of the renewable gasoline (1.7 $\mathrm{gCO}_{2} \mathrm{e} / \mathrm{MJ}$ for the in-situ process, $1.2 \mathrm{gCO}_{2} \mathrm{e} / \mathrm{MJ}$ for the ex-situ process) by up to $14 \%$ depending on the loading rate. $\mathrm{CoMo} / \mathrm{Y}^{-}-\mathrm{Al}_{2} \mathrm{O}_{3}$ had a greater $\mathrm{GHG}$ intensity $(9.6 \mathrm{~kg} \mathrm{CO} 2 \mathrm{e} / \mathrm{kg})$ than ZSM-5, however, it contributed approximately only $1 \%$ to the life-cycle GHG emissions of the renewable gasoline because of the small amount of this catalyst needed per $\mathrm{kg}$ of biofuel produced. Given that catalysts can contribute significantly to biofuel life-cycle GHG emissions depending on the GHG intensity of their production and their consumption rates, biofuel LCAs should consider the potential influence of catalysts on LCA results.
\end{abstract}

Keywords: catalyst production, life cycle analysis, biofuels, fast pyrolysis, spent catalyst treatment.

\title{
1. Introduction
}

Catalysts are an important element of biofuel production and have advanced the production of fuels from biomass feedstocks. For example, lignocellulosic biomass can be converted into transportation fuels through several pathways such as pyrolysis, liquefaction or gasification, followed by catalytic upgrading processes (e.g. hydrotreating). Catalysts can improve fuel yield and quality, control selectivity, and minimize hydrogen consumption in the hydrotreating process [1]. According to Dutta et al. [2], a key component of the success of pyrolysis pathways is the advancement in catalyst technology.

Despite the importance of catalysts in the biofuel supply chain, these compounds are often excluded from biofuel life cycle analysis (LCA). LCA can be used to assess potential greenhouse gas (GHG) emissions reductions associated with biofuels [3, 4, 5, and 6]. A biofuel's life-cycle GHG emissions influence its eligibility under key policies including the Renewable Fuel Standard (RFS) and the California Low Carbon Fuel Standard (LCFS). LCA includes all biofuel supply chain steps comprising raw material acquisition (fertilizer production, feedstock farming, harvesting, and transportation) to feedstock conversion and end use. This analysis can be influenced by different variables in each stage of the life cycle, for example, in the feedstock production stage, feedstock yield and fertilizer application rate are very important inputs that can affect the LCA. In the conversion stage, energy consumption, product yield and the formation of co-products are critical LCA parameters. In this work, we discuss the influence of catalyst consumption on biofuel LCA for a specific case study, the production of renewable hydrocarbon fuels through in-situ and ex-situ pyrolysis. Although several studies have presented advances in catalytic technologies for the transformation of biomass into biofuels [7, 8, and 9], to our knowledge, very few studies have discussed the environmental impact of catalyst use in biofuel production. For instance, Snowden-Swan et al. [10], presented a life-cycle analysis (cradle- to-gate) of two catalysts' ( $\mathrm{NiMo} / \mathrm{Al}_{2} \mathrm{O}_{3}$ and $\mathrm{Ru} / \mathrm{C}$ ) production and 
the environmental impact of using these catalysts in the hydrotreating of fast pyrolysis bio-oil. They estimated that the contribution of catalyst consumption to conversion stage GHG emissions can vary between $0.5 \%$ and $5 \%$ depending on the co-product treatment method applied. Snowden-Swan et al. [10] did not, however, carry out a full LCA of the renewable hydrocarbon fuel product and therefore did not estimate the catalysts' influence on total life-cycle GHG emissions of the fuel. Jones et al. [1] estimated the contribution of catalyst consumption to biorefinery GHG emissions to be less than $1 \%$. One of the reasons that catalysts' influence has rarely been analyzed in the LCA of biofuel production is the lack of material and energy intensity data for their manufacture, recycling, and reclamation. Furthermore, information on catalyst loadings, lifetimes, and even specific compositions is often proprietary. LCA is a very useful tool that can allow us to identify more sustainable options in selection, design, and optimization of a product or process from the early stage to the end-of-life. For example, Azapagic 1999 [11] reviews the advantage of integrating of LCA into the early stages of process design and optimization. In this paper, however, we use LCA to identify which aspects of the catalyst production chain will have more impact on the environment and will affect to the overall biofuel production. We first describe and compare cradle-to-gate GHG emissions of these two catalysts $\mathrm{ZSM}-5 \mathrm{Pt} / \mathrm{\gamma}-\mathrm{Al}_{2} \mathrm{O}_{3}$, to lend insight into key drivers of the GHG intensity of catalysts themselves. We also discuss end-of-life treatment and recovery and the associated GHG emissions of molybdenum- and platinum-based catalysts. Next, we provide insights into how catalyst consumption ( $\left.\mathrm{ZSM}-5, \mathrm{CoMo} / \mathrm{\gamma}-\mathrm{Al}_{2} \mathrm{O}_{3}\right)$ influences life-cycle $\mathrm{GHG}$ emissions of renewable hydrocarbon fuels produced via in-situ and ex-situ pyrolysis.

\section{Materials and Methods}

We designed the Greenhouse gases, Regulated Emissions, and Energy use in Transportation -GREET ${ }^{\circledR}[12]$ catalyst module to include catalysts relevant to the conversion of biomass to biofuels [13]. The GREET ${ }^{\circledR}$ model, developed at Argonne National Laboratory, is a publicly available model that investigates the lifecycle energy use, GHG and air pollutant emissions, and water consumption of various vehicle technologies and transportation fuels. With regard to biofuels, the GREET model contains numerous types of biofuels (e.g. ethanol, biodiesel, renewable gasoline) produced from various biomass feedstocks (e.g. corn, soybeans, switchgrass) that have been subject to previous analysis [3, 4 and 14]. The module currently includes five catalysts: an alcohol synthesis catalyst produced with wood- or coal-derived activated carbon, a tar reforming catalyst, ZSM-5, CoMo/ $/-\mathrm{Al}_{2} \mathrm{O}_{3}$, and $\mathrm{Pt} / \mathrm{\gamma}-\mathrm{Al}_{2} \mathrm{O}_{3}$. In this paper, we focus on the latter three. We developed material and energy flow data for their production based on information in the technical literature and patents as described in Wang et al. [13] and summarized below. Supplementary Tables 1-3 summarize the energy and material inputs used in the supply chain of these catalysts. It is important to note that limited data regarding catalyst production material and energy consumption necessitated reliance on engineering calculations and estimates to generate these results. In addition, the material and energy consumption values we report herein are estimates based on publicly available information. Actual energy and material consumption at these facilities could vary. These material and energy flows were incorporated into the catalyst module and paired with the production of renewable hydrocarbon fuels from in-situ and ex-situ pyrolysis of a blended woody feedstock $[2,15]$. 


\subsection{Production of Platinum on $\gamma$ - Alumina $\left(\mathrm{Pt} / \mathrm{\gamma}-\mathrm{Al}_{2} \mathrm{O}_{3}\right)$}

$\mathrm{Pt} / \mathrm{\gamma}-\mathrm{Al}_{2} \mathrm{O}_{3}$ can be used in several different chemical transformations relevant to biomass conversion including aqueous phase reforming of biomass [16]. The platinum group metal (PGM) content of these catalysts is typically between 0.1 and $5.0 \%$. Figure 1 presents the steps involved in the production of this catalyst. The main part of this process is the platinum deposition on alumina which is achieved using aqua regia. Aqua regia typically consists of a 1:3 mixture of concentrated nitric and hydrochloric acids. This process also uses a soluble Pt-containing salt such as chloroplatinic acid $\left(\mathrm{H}_{2} \mathrm{PtCl}_{6}\right)$. Details of the $\gamma$-alumina support and catalyst production are found in [13], while Benavides et al. [17] report information regarding platinum production.

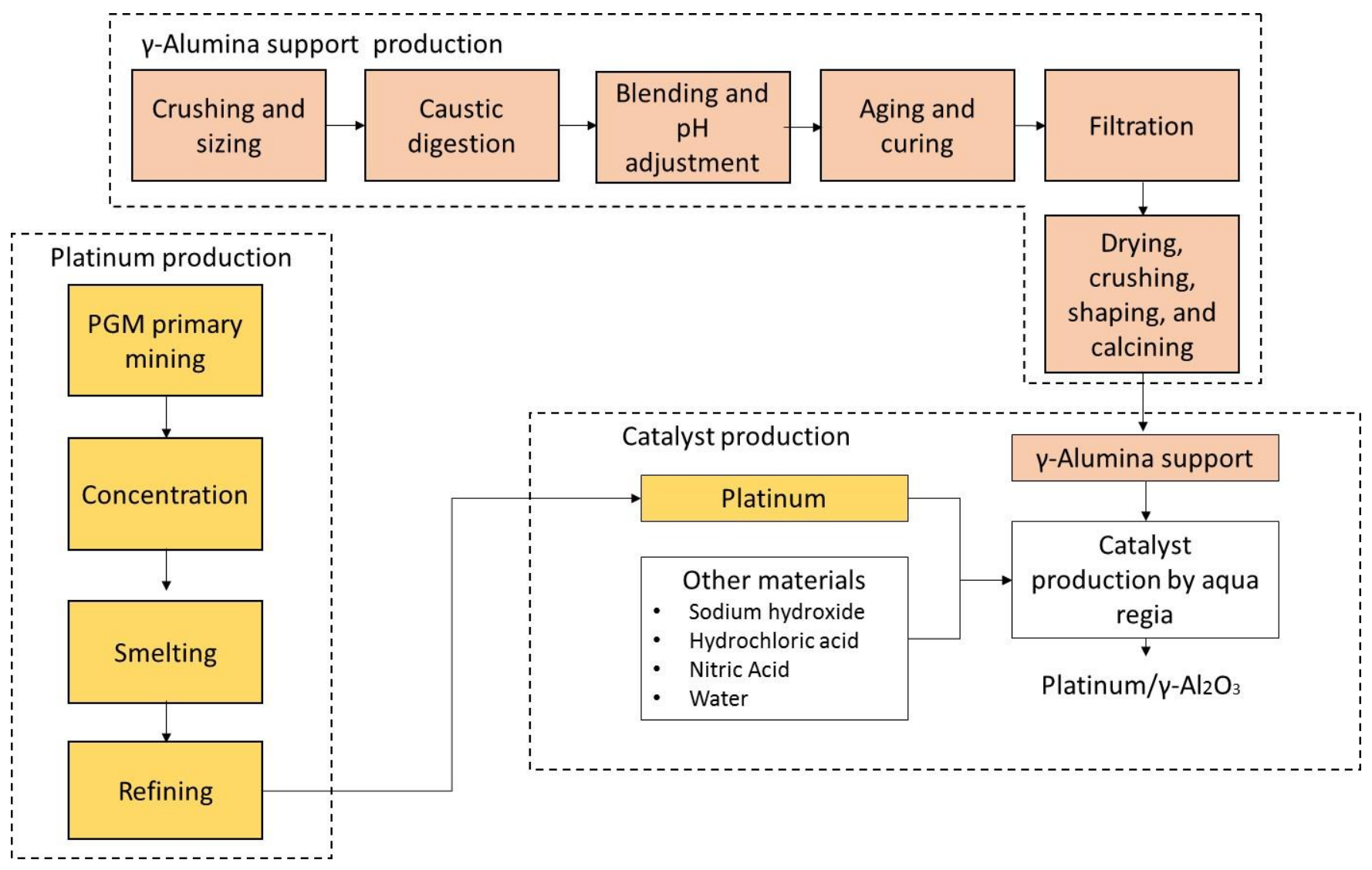

Figure $1 \mathrm{Pt}$ /alumina-supported catalyst supply chain

Platinum comes from the mining, concentration, and refining of PGMs. Its production is very complex, costly, and energy-intensive. PGM are mostly mined in South Africa and Russia, but mines in North and South America also produce PGM, nickel, and copper. We focused on and incorporated data from Anglo American Platinum [18] in South Africa because this country produces the majority (around 70\%) of PGM worldwide [18]. PGM ore mining consumes more energy than other steps in PGM production although the low PGM content in ore (typically $5 \mathrm{~g} /$ ton ore $[20,21]$ ) renders PGM extraction and processing energy intensive as well [17]. Low PGM content also results in significant water consumption and mining waste. Air conditioning of mines in South Africa leads to significant electricity consumption to run air compression units, pumps, and ventilation and refrigeration units. On average, electricity production in South Africa is coal-intensive, which contributes to high GHG emissions from South African-produced PGM. In 2012, most 
of the electricity produced in South Africa came from coal (93\%) and only 5\% came from nuclear [22]. As a point of comparison, $39 \%$ of electricity in the U.S. comes from coal, $27 \%$ from natural gas, and $19 \%$ from nuclear power [23]. Correspondingly, electricity production in South Africa is very GHG-intensive.

From cradle-to-gate, platinum production GHG emissions are $113 \mathrm{kgCO}_{2} \mathrm{e} / \mathrm{kg}$ [17]. This result agrees with the outcome presented by Snowden-Swan et al. [10], who, using different data from that which we used in our analysis, reported a nearly identical GHG intensities for platinum production in South Africa of 112 $\mathrm{kgCO}_{2} \mathrm{e} / \mathrm{kg}$. Platinum production GHG emissions are high because the $72 \%$ of the energy input to the energy-intensive process is electricity, which is produced largely from coal.

\subsection{Production of Molybdenum and cobalt on $\gamma$ - alumina $\left(\mathrm{CoMo} / \gamma-\mathrm{Al}_{2} \mathrm{O}_{3}\right)$}

$\mathrm{CoMo} / \gamma-\mathrm{Al}_{2} \mathrm{O}_{3}$ can be used in lignin conversion via hydrogenation to high-value chemical compounds [16]. The specific formulation of $\mathrm{CoMo} / \gamma-\mathrm{Al}_{2} \mathrm{O}_{3}$ catalysts vary widely depending in part upon the desired catalyst characteristics. These catalysts can be produced from a variety of feedstocks with different preparation techniques. Figure 2 describes a process that uses the common incipient wetness impregnation (IWI) method. Wang et al. [13] presents more details about the production of this catalyst.

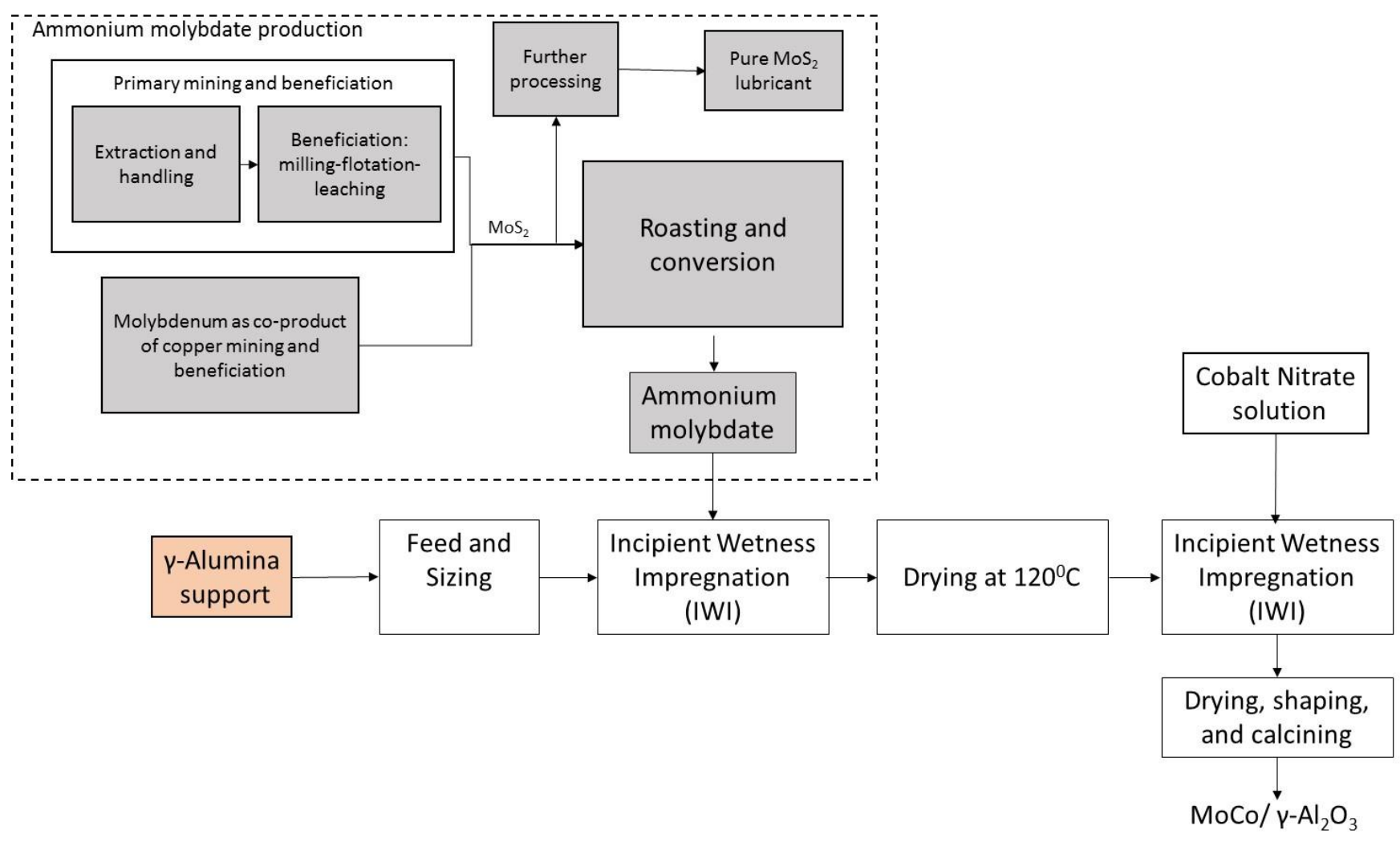

Figure 2 CoMo /alumina-supported catalyst supply chain 
One important precursor of this catalyst is ammonium molybdate. This material comes from the extraction of molybdenum metal that is then concentrated to molybdenum disulfide (i.e., $\mathrm{MoS}_{2}$ ). The production process of ammonium molybdate is described in Figure 2. Molybdenum is mined, either as a primary deposit or as co-product of copper mining. About $50 \%$ of the global supply of molybdenum is produced as a co-product of copper mining [24]. As a result of to the small molybdenum's low concentration (0.01 - $0.25 \mathrm{wt} \%$ ) in ore, a significant amount of energy is need in the extraction stage. Once the ore is excavated from the mine, the molybdenum disulfide is concentrated in the beneficiation process. When copper and molybdenum ores are mined together, a flotation step separates molybdenum disulfide from copper sulfide. The resulting $\mathrm{MoS}_{2}$ concentrate contains between 85 and $96 \mathrm{wt} \% \mathrm{MoS}_{2}$, approximately $58 \mathrm{wt} \% \mathrm{Mo}[25]$. The final step is roasting the concentrate to produce molybdenum trioxide $\left(\mathrm{MoO}_{3}\right)$. This $\mathrm{MoO}_{3}$ is then converted to a number of other products [26, 27], including ammonium molybdate, which is the precursor for the catalyst discussed here. Benavides et al. [17] report more information regarding material and energy consumption in the production of ammonium molybdate and drew the majority of data from Climax Molybdenum Company [28].

\subsection{Production of alumino-silicate zeolite catalyst (ZSM-5)}

ZSM-5 or alumino-silicate zeolite is widely used in the petroleum industry as a heterogeneous catalyst, and it can also be used for catalyzing chemical reactions for biofuel production. Figure 3 describes the steps in the preparation of ZSM-5 catalyst per [29], which is described further in the supporting information and in [13].

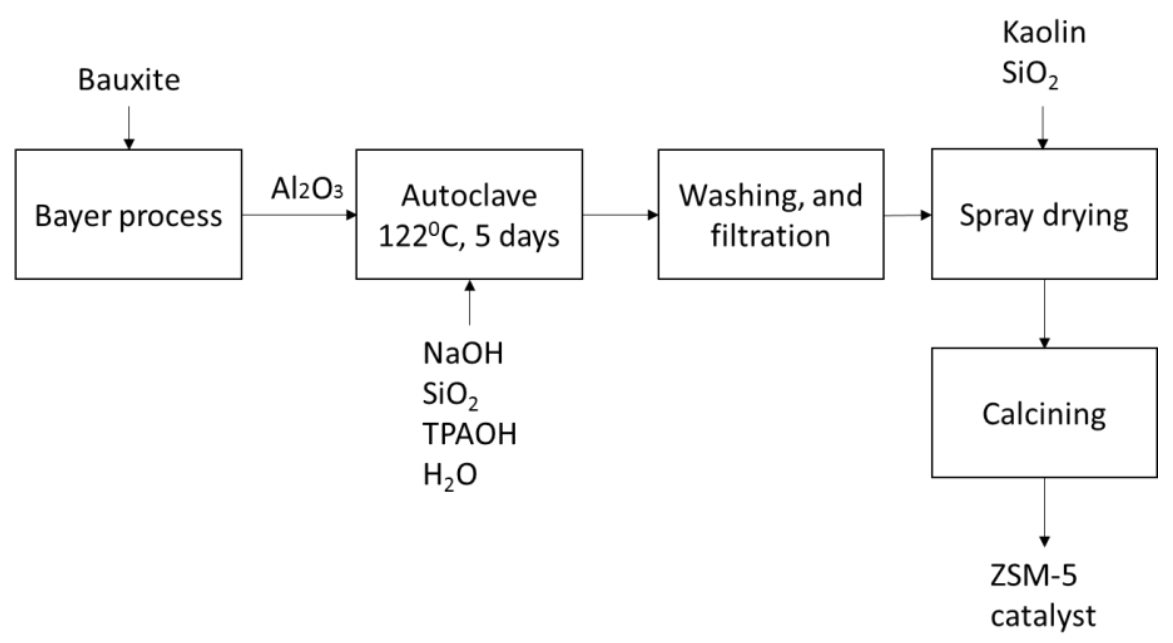

Figure 3 ZSM-5 catalyst supply chain

\subsection{In-situ and ex-situ pyrolysis of a blended woody feedstock}

To examine the influence of catalysts on the life-cycle GHG emissions of biofuels, we examined the case study of producing renewable gasoline from in-situ and ex-situ fast pyrolysis of a blended woody feedstock (pulpwood, forest residues, switchgrass, and construction and demolition (C\&D) waste). GREET data for poplar were used for pulpwood in the feedstock blend. Material and energy flows for feedstock logistics 
and the conversion processes were adopted from Idaho National Laboratory [13] and Dutta et al. [2]. Fast pyrolysis involves rapid heating of biomass at high temperatures (i.e., $500{ }^{\circ} \mathrm{C}$ ) in the absence of air. The conversion process includes either an in-situ or ex-situ step for upgrading the pyrolysis vapors. In the insitu design, the vapor upgrading takes place within the fast pyrolysis reactor while upgrading in the exsitu design occurs in a subsequent reactor. The design capacity is 2,205 dry tons biomass per day which resulted in a fuel yield of 56 and 36 gallons of renewable gasoline per dry tons of biomass for in-situ and ex-situ upgrading, respectively [2]. For renewable diesel production the yield was 19 and 39 gallons per day per dry tons of biomass in the cases of in-situ and ex-situ upgrading, respectively. The plant uptime is $90 \%$ for the entire year (i.e., 7,884 operation hours per year). ZSM-5 catalyst is used in the pyrolysis and vapor upgrading section of the conversion process while $\mathrm{CoMo} / \mathrm{\gamma}-\mathrm{Al}_{2} \mathrm{O}_{3}$ catalyst is consumed in the hydroprocessing step. Given the relatively high GHG intensity of producing ZSM-5 and CoMo-based catalysts (Table 2), we adopted these pathways for analysis to assess the influence of catalysts on biofuel life-cycle GHG emissions.

The feedstock-to-fuel pathway involves the stages presented in Figure 4. The first stage is feedstock production, followed by feedstock logistics which includes storage, preprocessing and preparation. Then, the feedstock is transported to the conversion facility and converted to renewable fuel. The last stage is the transportation and distribution of the fuel product. The key parameters for feedstock transportation, farming, and preprocessing are summarized in the supplementary information (see supplementary Table 5).

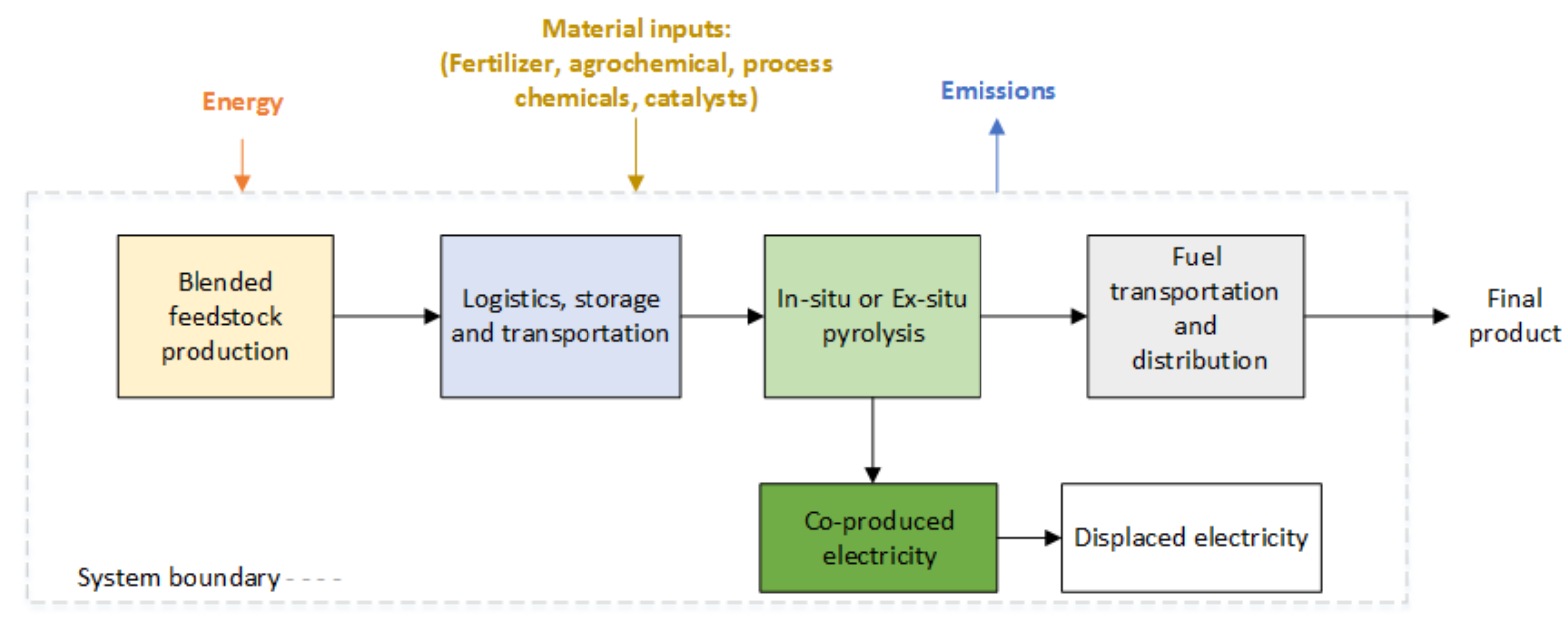

Figure 4 General stages considered in the LCA of hydrocarbon fuel production via pyrolysis

Table 1 presents conversion stage key parameters. According to Dutta et al. [2], electricity is produced from the burning of char, coke, and off-gases that meets the internal electricity demand Excess electricity is sold to the grid. The process requires small amounts of natural gas and diesel fuel. Natural gas is used to supplement hydrogen production from off-gases. The in-situ process consumes more ZSM-5 than the ex-situ process because in the former, the catalyst mixes with biomass, char and ash which affects catalyst performance and maintenance.

The two pyrolysis processes produce renewable gasoline, diesel, and electricity; a method must therefore be selected to distribute energy and emissions burdens among these three products. Given that the two fuel products are energy products with a similar application, we adopted the energy allocation co-product 
treatment method for them. The displacement method was applied to the electricity co-product; we assumed electricity generated with the average U.S. grid was displaced and assigned a co-product credit to the two liquid fuel co-products accordingly.

Table 1 Key parameters for the conversion of the blended woody feedstock into hydrocarbon fuel [2]

\begin{tabular}{|l|c|c|}
\hline Method of upgrading pyrolysis vapor & In-situ design & Ex-situ design \\
\hline Material and energy input & & \\
Biomass (g/kg main product) & 4200 & 4100 \\
Process fuels (MJ/kg main product) & 0.13 & 0.21 \\
\hline Yield (gal/dry ton of blended feedstock) & 75 & 78 \\
\hline Process Fuel Share & & \\
NG (MJ/kg main product) & $0.06(46 \%)$ & $0.13(66 \%)$ \\
Diesel (MJ/kg main product) & $0.07(54 \%)$ & $0.07(34 \%)$ \\
\hline Volumetric Share of Products & $73 \%$ & $45 \%$ \\
Pyrolysis Gasoline & $27 \%$ & $55 \%$ \\
Pyrolysis Diesel & & \\
\hline Co-product & 0.93 & 0.56 \\
Electricity (MJ/kg main product) & & \\
\hline Other material inputs (g/ kg main product) & 8 & 4.85 \\
ZSM-5 Catalyst & 0.44 & 0.44 \\
Hydrotreating catalyst- (CoMo/ $/$ - $^{-} \mathrm{I}_{2} \mathrm{O}_{3}$ ) & 6.61 & 6.17 \\
Sodium hydroxide & & \\
\hline
\end{tabular}

\subsection{Treatment of the spent catalyst}

Although it is uncertain how a bio-refinery's spent catalyst would be dealt with, it is probable that the metal-containing catalysts would need to undergo a recovery process because they may be considered too contaminated to be placed in a landfill. This section discusses recovery treatments for molybdenumand platinum-based catalysts. More details about these treatments are found in [13]. On the other hand, recovery of spent ZSM-5 catalyst is generally considered economically infeasible and is not widely practiced [30] so we do not address it herein.

It is unlikely that individual refiners and potential bio-processors would reprocess their own spent catalysts but would ship to companies for further treatment. For instance, molybdenum-based spent catalyst can be sent to Gulf Chemical and Metallurgical Corporation (GCMC), which handles spent catalysts from a wide range of hydroprocessing oil refineries in the U.S to recover molybdenum, vanadium, nickel, cobalt, and alumina [31]. The GCMC feedstock is a blend of spent catalysts from a number of refiners; therefore, its characteristics and composition presumably varies widely. The treatment process to recover molybdenum includes roasting the spent catalyst with air and soda ash at temperatures up to $800^{\circ} \mathrm{C}$, followed by a grinding and leaching stage, and finally purification and separation to remove contaminants and recover vanadium and molybdenum metals. A spent molybdenum-based catalyst from a bio-refinery would likely have a different composition [13] compared to petroleum refinery spent catalysts. We use as a basis the recovery process published for petroleum refining-derived spent catalyst. Compared to this type of catalyst waste, there would likely be little recoverable vanadium associated with spent biorefinery catalysts, but the slag would contain some $\mathrm{Fe}, \mathrm{Ca}, \mathrm{K}$, and other metals whereas slag from treatment of petroleum refinery catalysts would not. We considered how the process energy consumption would change given the difference in composition of the spent catalyst feed. 
Recovery processes for platinum-based catalysts are generally hydrometallurgical (solution extraction using aqua regia), pyrometallurgical using a metal such as $\mathrm{Fe}$ or $\mathrm{Cu}$ as a flux or carrier, or gas-phase volatilization or selective chlorination [32,33, and 34]. In this paper, we only discuss the first two options. In the aqua regia extraction process, the spent catalyst is calcined to burn off carbonaceous deposits. Calcination at $870^{\circ} \mathrm{C}$ has been suggested [35] to convert the alumina support from the $\gamma$ to $\alpha$ phase, thereby greatly reducing the surface area and forming a relatively inert surface such that acids cannot dissolve the alumina. The catalyst is partially cooled and contacted with aqua regia. The solids are filtered and the solution is treated to recover solid Pt. It is assumed that the recovered acids are recycled within the process. The various PGM can be separated using ion exchange or chromatography using their chlorocomplexes [36]. The pyrometallurgical spent catalyst treatment process has been reviewed by Benson et al. [37]. In this process the recycled solids -with the addition of limited amounts of Fe or $\mathrm{Cu}$ - are crushed and heated to temperatures in the range of 1500 to $1700^{\circ} \mathrm{C}$ to isolate PGM solids in a slag layer. Material and energy inputs involve in the recovery treatments discussed here can be found in the supplementary information (Section 2).

\section{Results and discussion}

\subsection{GHG emissions and fossil fuel consumption of catalyst production}

Table 2 summarizes the cradle-to-gate fossil fuel consumption and GHG emissions for the three catalysts discussed in this paper. CoMo/ $/-\mathrm{Al}_{2} \mathrm{O}_{3}$ has the largest cradle-to-gate $\mathrm{GHG}$ emissions. Emissions associated with production of $\mathrm{ZSM}-5$ and $\mathrm{Pt} / \mathrm{\gamma}-\mathrm{Al}_{2} \mathrm{O}_{3}$ are lower and comparable. In the case of the $\mathrm{ZSM}-5$ catalyst, the GHG emissions are dominated by the production of ZSM-5 itself (Figure 5). This result is influenced by the GHG emissions due to production of TPAOH and $\mathrm{SiO}_{2}$ gel and the energy consumed during the process. The contribution of kaolin and $\mathrm{SiO}_{2}$ gel are only $4 \%$ and $9 \%$, respectively, of the cradle-to-gate GHG emissions of the catalyst. The GHG emissions of the CoMo $/ \gamma-\mathrm{Al}_{2} \mathrm{O}_{3}$ catalyst are dominated by the production of $y$-alumina and ammonium molybdate (Figure 5). The cradle-to-gate GHG emissions of these two compounds were estimated to be 4.3 and $16 \mathrm{~kg} \mathrm{CO}_{2} \mathrm{e} / \mathrm{kg}$, respectively. Although ammonium molybdate only represents $25 \mathrm{wt} \%$ of the catalyst, it is GHG intensive and contributes notably to the cradle-to-gate emissions of the catalyst.

Table 2 Fossil fuel consumption and GHG emissions of the compounds in the GREET catalyst module

\begin{tabular}{lccc}
\hline \multicolumn{1}{c}{ Cradle-to-Gate Result } & ZSM-5 Catalyst & $\mathrm{CoMo} / \mathrm{\gamma}-\mathrm{Al}_{2} \mathrm{O}_{3}$ & $\mathrm{Pt} / \mathrm{\gamma}-\mathrm{Al}_{2} \mathrm{O}_{3}$ \\
\hline Fossil fuel consumption $(\mathrm{MJ} / \mathrm{kg})$ & 115 & 128 & 91 \\
$\mathrm{GHG}$ emissions $(\mathrm{kg} \mathrm{CO} 2 \mathrm{e} / \mathrm{kg})$ & 7.7 & 9.6 & 7.1 \\
\hline
\end{tabular}

The major contributors of the cradle-to-gate GHG emissions of the $\mathrm{Pt} / \mathrm{\gamma Al}_{2} \mathrm{O}_{3}$ catalyst are platinum and $\gamma$ alumina (Figure 5). Platinum is only $2 \%$ of the catalyst mass, but it is a major contributor to catalyst GHG intensity because it is a GHG-intensive metal as described earlier. 


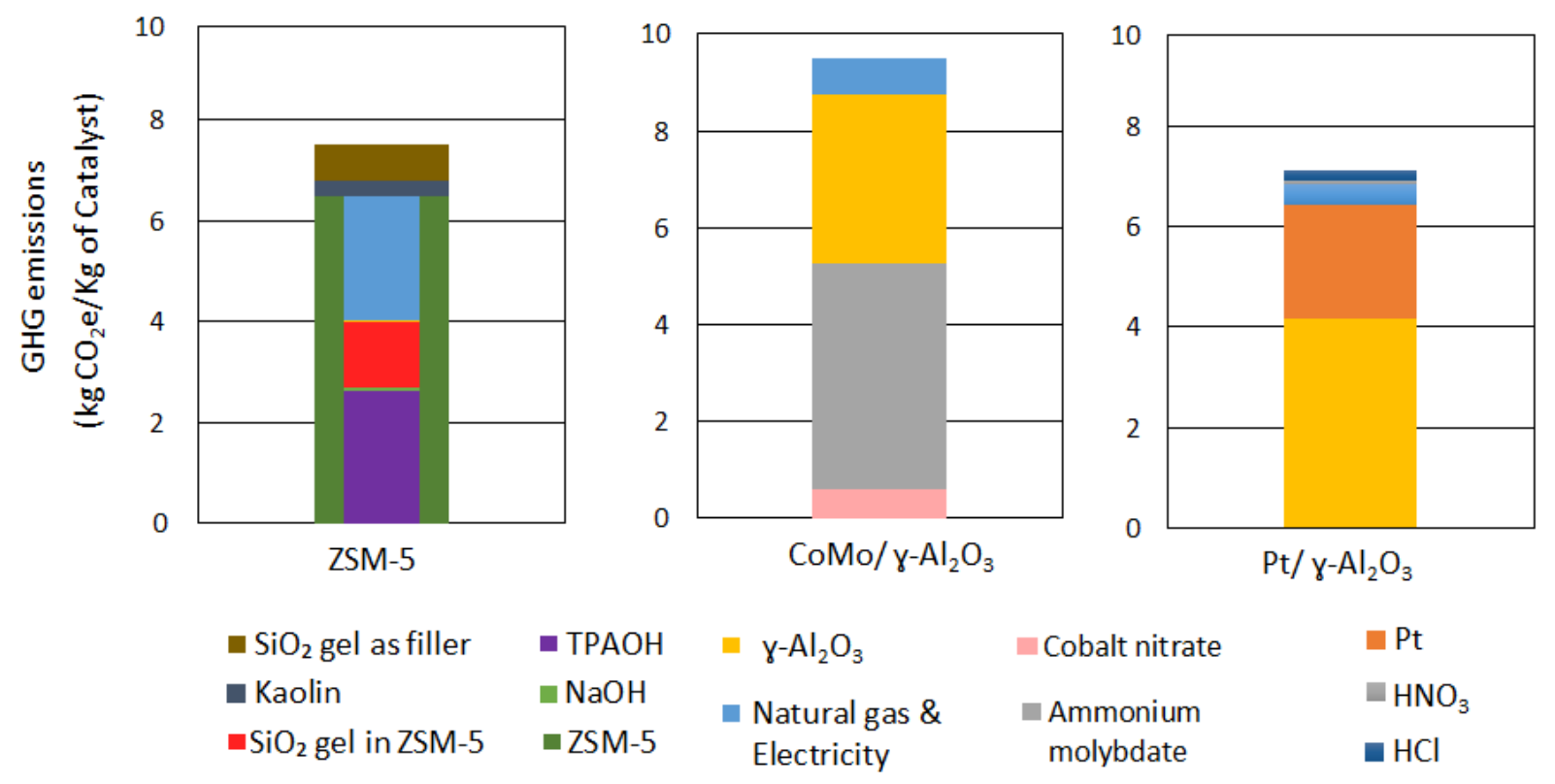

Figure 5 Cradle-to-gate GHG emissions for ZSM-5, MoCo/ $/-\mathrm{Al}_{2} \mathrm{O}_{3}$, and $\mathrm{Pt} / \mathrm{\gamma}-\mathrm{Al}_{2} \mathrm{O}_{3}$

Table 3 summarizes the GHG emissions of different spent catalyst treatments considered in this paper. Treatment of molybdenum-based catalysts is more energy intensive than treatment of platinum-based catalysts, which translates to a higher GHG intensity for the latter. The GHG emissions of the recovered molybdenum (e.g. bio-based) are included to the life-cycle analysis of the renewable gasoline which is explained next.

Table 3 Comparison of GHG emissions of different spent catalyst treatments for molybdenum and platinum based catalysts

\begin{tabular}{lcc}
\hline Spent Catalyst & Spent catalyst Treatment & $\begin{array}{c}\text { GHG emissions (kg CO}{ }_{2} \mathrm{e} / \mathrm{kg} \text { spent } \\
\text { catalyst) }\end{array}$ \\
\hline Molybdenum based & Petrochemical & 3.8 \\
& Bio-based & 1.0 \\
Platinum based & Agua regia & 0.8 \\
& Pyrometallurgical & 0.2 \\
\hline
\end{tabular}

\subsection{Catalyst influence on the life-cycle GHG emissions of renewable hydrocarbon fuels produced from in-situ and ex-situ pyrolysis}

In this section, we assess the environmental impacts of catalyst consumption in the production of in-situ and ex-situ pyrolysis of a blended woody feedstock. The breakdown of farm-to-pump life-cycle GHG emissions of renewable gasoline produced via these two pathways is presented in Figure 6. The GHG emissions for farming activity, fertilizer production and use, transportation and distribution, and preprocessing have similar shares in the two designs. For example, the farming activity contributes $23 \%$ and $21 \%$ of net life-cycle GHG emissions for the in-situ and ex-situ cases, respectively. For fertilizer production the contribution is $8 \%$ and $7 \%$; for transportation it is $12 \%$ and $11 \%$. Finally, the preprocessing 
step contributes $65 \%$ and $59 \%$ of net life-cycle GHG emissions for the in-situ and ex-situ cases, respectively. These contributions are similar because the composition of the feedstock blend is constant between the two cases (see Supplementary Table 5). In the ex-situ case, the absolute contribution of these steps is lower because the fuel yield is higher. In both designs, the largest contributor to life-cycle GHG emissions is the preprocessing stage because a good deal of energy is invested in the cleaning and removal of undesirable material from the feedstock.

The contributions of biorefinery stage GHG emissions to life-cycle GHG emissions are $19 \%$ and $18 \%$ in the in-situ and ex-situ cases, respectively. The yield, which is slightly lower in the in-situ case, contributed to this difference (See Table 1). Comparing only the ZSM-5 contribution, this catalyst contributes more to net GHG emissions in the in-situ case $\left(1.4 \mathrm{gCO}_{2} \mathrm{e} / \mathrm{MJ}, 12 \%\right)$ than in the ex-situ case $\left(0.8 \mathrm{gCO}_{2} \mathrm{e} / \mathrm{MJ}, 7 \%\right)$. This result is expected because the in-situ case consumes more catalyst. However, the GHG emissions associated with consumption of process energy in the conversion step are $11 \%$ less in the in-situ case because this configuration requires less energy than the ex-situ case, permitting more electricity export. The renewable gasoline in this case receives a $39 \%$ higher electricity displacement credit. If no electricity credits were included in the analysis, the overall GHG emissions would be higher $\left(15.5 \mathrm{gCO}_{2} \mathrm{e} / \mathrm{MJ}\right.$ in the in-situ case compared to $13.9 \mathrm{gCO}_{2} \mathrm{e} / \mathrm{MJ}$ in the ex-situ case). The contribution of the other biorefinery inputs ( $\mathrm{CoMo} / \mathrm{Y}-\mathrm{Al}_{2} \mathrm{O}_{3}$ and other materials) to life-cycle $\mathrm{GHG}$ emissions remain the same in both designs (less than $1 \%$ and $3 \%$, respectively). Although $\mathrm{CoMo} / \mathrm{\gamma}-\mathrm{Al}_{2} \mathrm{O}_{3}$ is $\mathrm{GHG}$ intensive to produce, as discussed in Section 3.1, the net catalyst consumption in hydroprocessing is very low. Therefore, this catalyst does not contribute meaningfully to life-cycle GHG emissions of the fuel. For both cases investigated, the estimated GHG emissions reduction potential is $87 \%$ compared to conventional gasoline (which has lifecycle GHG emissions of $92.3 \mathrm{gCO}_{2} \mathrm{e} / \mathrm{MJ}$ ). This reduction meets the $60 \% \mathrm{GHG}$ reduction threshold in the Renewable Fuel Standard for cellulosic biofuels. 


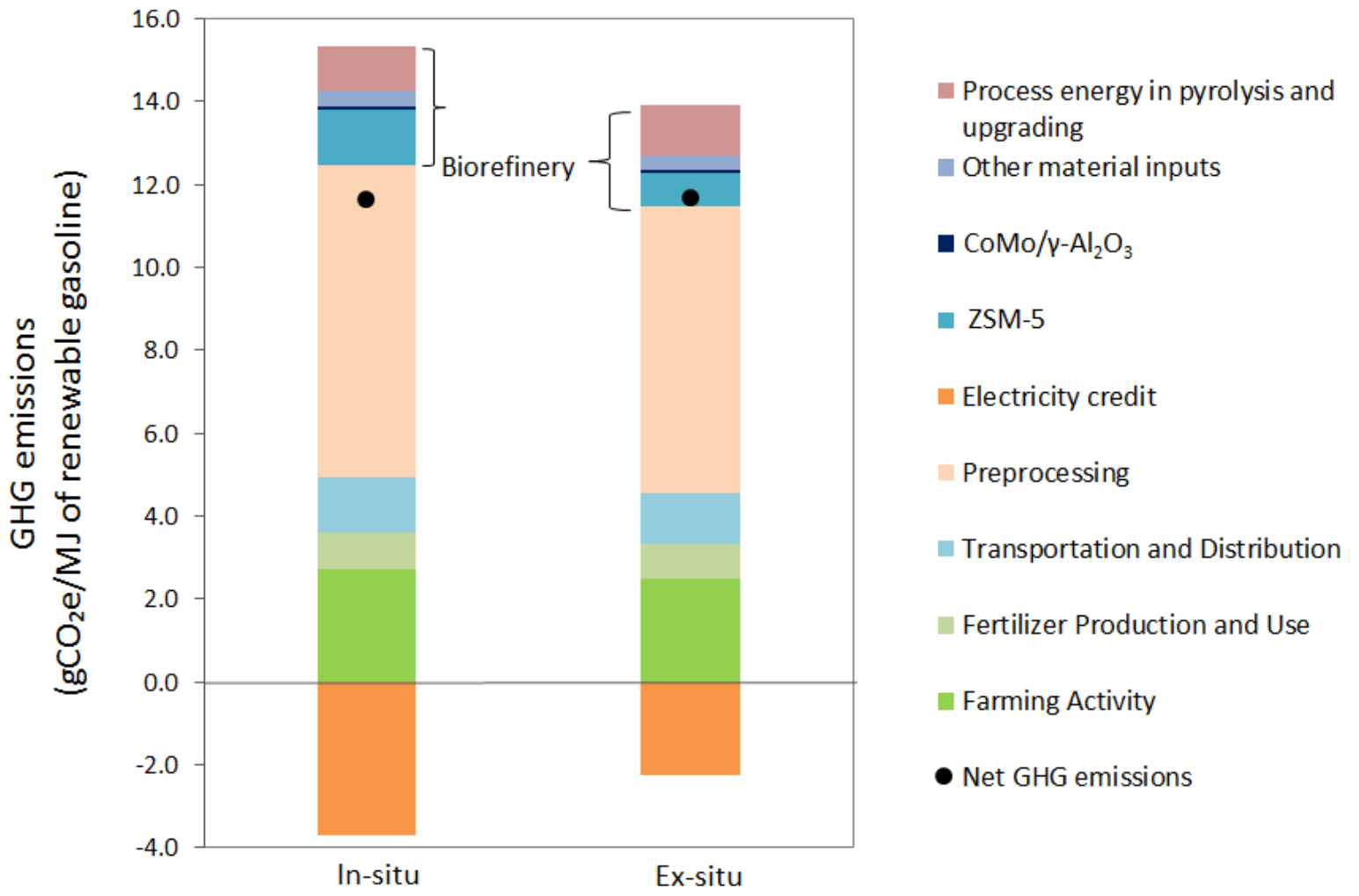

Figure 6 Breakdown of farm-to-pump GHG emissions in the in-situ and ex situ fast pyrolysis of a blended woody feedstock

Catalyst lifetime and loading rates are major drivers of process economics and can be major drivers of lifecycle GHG emissions of fuels produced with catalysts if catalyst lifetimes are very short or loadings high. A sensitivity analysis was therefore performed to explore the effects of varying the ZSM-5 catalyst consumption on the life-cycle GHG emissions of the renewable gasoline (Table 4). When the catalyst input varies by plus or minus $25 \%$, the contribution of the catalyst to the life-cycle GHG emissions varies from $9 \%$ to $14 \%$ and from $5 \%$ to $9 \%$ to the life cycle GHG contribution in the in-situ and ex-situ design, respectively. Therefore, in this case reducing the amount of catalyst consumed, while likely desirable to reduce processing costs, will not significantly affect the life-cycle GHG emissions of the biofuel.

On the other hand, in this analysis the amount of catalyst consumed to produce one MJ of renewable gasoline is based on a catalyst lifetime of two years [2]. If the catalyst lifetime of ZSM-5 is reduced to one year, which means that the amount of catalyst consumed over two years doubles, the life-cycle GHG emissions of renewable gasoline are notably influenced. The contribution of the catalyst to renewable gasoline life-cycle greenhouse gas emissions will range from $12 \%$ to $21 \%$ and from $7 \%$ to $13 \%$ in the insitu and ex-situ cases, respectively. However, for both cases, life-cycle GHG emissions will still be significantly less (86\%) than conventional gasoline. 
Table 4 Impact of varying the ZSM-5 catalyst input on life-cycle GHG emissions of renewable gasoline

\begin{tabular}{|c|c|c|c|}
\hline \multirow[b]{2}{*}{ ZSM-5 loading } & \multicolumn{3}{|c|}{ Scenarios } \\
\hline & $-25 \%$ & Base & $+25 \%$ \\
\hline \multicolumn{4}{|c|}{ Contribution to net life-cycle GHG emissions } \\
\hline In-situ & $9 \%$ & $12 \%$ & $14 \%$ \\
\hline Ex-situ & $5 \%$ & $7 \%$ & $9 \%$ \\
\hline \multicolumn{4}{|c|}{ Net GHG $\left(\mathrm{CO}_{2} \mathrm{e} / \mathrm{MJ}\right.$ of renewable gasoline) } \\
\hline In-situ & 11.3 & 11.6 & 12 \\
\hline Ex-situ & 11.5 & 11.7 & 11.9 \\
\hline
\end{tabular}

Although substantially less CoMo $/ \mathrm{Y}-\mathrm{Al}_{2} \mathrm{O}_{3}$ catalyst is consumed compared to the ZSM-5 catalyst (Table 1 ), a similar sensitivity analysis was also performed to consider an increase in the consumption of this catalyst. In addition, because this catalyst could deactivate quickly in water [38, 39, 40, 41, and 42], its lifetime may be shorter than the value we adopted in the base case. Therefore, when the catalyst lifetime is reduced from two years [2] to six months, which translates to a four-fold catalyst consumption rate increase, consumption of this catalyst contributes only $3 \%$ to life-cycle GHG emissions of renewable gasoline. In summary, we do not expect changes in $\mathrm{CoMo} / \mathrm{\gamma}-\mathrm{Al}_{2} \mathrm{O}_{3}$ lifetime to influence life-cycle GHG emissions of the renewable gasoline we considered in this analysis.

\section{Conclusion}

Catalysts' influence on the life-cycle GHG emissions of a biofuel is dictated by the GHG intensity of producing the catalyst and its consumption rate. Although some catalysts can be very GHG-intensive to produce, if catalyst life time is long and/or consumption rates are low, a catalyst will likely have a minimal influence on the life-cycle GHG emissions of biofuels on a farm-to-wheels basis. This scenario applied in the case of $\mathrm{CoMo} / \mathrm{\gamma}-\mathrm{Al}_{2} \mathrm{O}_{3}$ as used in the two fast pyrolysis designs we considered. It should be noted that if secondary metal sourcing were incorporated into the analysis of this catalyst's production, that is the metals would be sourced from recycling processes rather than from virgin materials, impacts could be even lower. The consumption rate of $\mathrm{ZSM}-5$, which is likely more GHG intensive than $\mathrm{CoMo} / \mathrm{Y}-\mathrm{Al}_{2} \mathrm{O}_{3}$ is 22 36 times greater than this bimetallic catalyst and its contribution to renewable gasoline life-cycle GHG emissions could be as high as $14 \%$. This catalyst is not economical to recycle, so secondary sourcing is not possible. Given this outcome, it is not advisable to ignore catalysts' contribution to biofuel life-cycle GHG emissions. Including this contribution can be difficult given the proprietary nature of catalyst composition, preparation, and life times in various processes. In the absence of data, one approach to gain a sense of what a catalyst's contribution to biofuel life-cycle GHG emissions could be to use a proxy GHG intensity tapping results from GREET or other LCA tools and conduct a sensitivity analysis.

\section{Acknowledgement}

This work was supported by the Bioenergy Technologies Office (BETO) of the Office of Energy Efficiency and Renewable Energy of the United States Department of Energy [contract number DE-AC02- 
06CH11357]. We thank Jarod Kelly, Qiang Dai, and Linda Gaines of Argonne for helpful discussions regarding metals mining. We further thank Alicia Lindauer, Kristen Johnson, and Zia Haq of BETO.

\section{References}

[1] Jones S, Meyer P, Snowden-Swan L J, Padmaperuma A, Tan E, Dutta A, Cafferty K, 2013 Process design and economics for the conversion of lignocellulosic biomass to hydrocarbon fuels, Fast pyrolysis and hydrotreating bio-oil pathway (Richland WA: Pacific Northwest National Laboratory PNNL-23053, Golden CO: National Renewable Energy Laboratory NREL/TP- 5100-61178) U.S. DEpartment of Energy Bioenergy Technologies Office

[2] Dutta A, Sahir A, Tan E, Humbird D, Snowden-Swan L J, Meyer P, Lukas J, 2015 Process design and economics for the conversion of lignocellulosic biomass to hydrocarbon fuels: thermochemical research pathways with in-situ and ex-situ upgrading of fast pyrolisis vapors. (Richland WA: Pacific Northwest National Laboratory PNNL-23053, Golden CO: National Renewable Energy Laboratory NREL/TP- 510061178) U.S. Department of Energy Bioenergy Technologies Office

[3] Qin Z, Dunn J, Kwon H, Mueller S, Wander M, 2016 Influence of spatially dependent, modeled soil carbon emission factors on life-cycle greenhouse gas emissions of corn and cellulosic ethanol GCB Bioenergy doi:10.1111/gcbb.12333

[4] Canter CE, Dunn JB, Han J, Wang Z, Wang M, 2016 Policy implications of allocation methods in the life cycle analysis of integrated corn and corn stover ethanol production BioEnergy Research 9 77-87

[5] Wang Z, Dunn J, Han J, Wang M, 2015 Influence of corn oil recovery on life-cycle greenhouse gas emissions of corn ethanol and corn oil biodiesel Biotechnol Biofuels 8 1-10

[6] Shonnard D, Klemetsrud B, Sacramento-Rivero J, Navarro-Pineda F, Hilbert J, Suppen N, Donovan R, 2015 A Review of Environmental Life Cycle Assessments of Liquid Transportation Biofuels in the Pan American Region Environmental Management 56 1356-1376

[7] Elliot D, 2007 Historical developments in hydroprocessing bio-oil Energy \& Fuels 21 1792-1815

[8] Wang H, Male J, Wang Y, 2013 Recent advances in hydrotreating of pyrolisis bio-oil and its oxygencontaining model compounds ACS Catalysis 3 1047-1070

[9] Faba L, Diaz E, Ordóñez S, 2015 Recent developments on the catalytic technologies for the transformation of biomass into biofuels: a patent survey Renewable and Sustainable Energy Reviews $\mathbf{5 1}$ 273-287

[10] Snowden- Swan L J, Spies K.A., Lee G.J., Zhu Y, 2016 Life cycle greenhouse gas emissions analysis of catalysts for hydrotreating of fast pyrolysis bio-oil. Biomass and Bioenergy 86 136-145

[11] Azapagic A, 1999. Life cycle assessment and its application to process selection, design and optimization. Chemical Engineering Journal 73 1-21 
[12] GREET ${ }^{\circledR} 2015$ Greenhouse gases, Regulated Emissions, and Energy use in Transportation Argonne National Laboratory (http://greet.es.anl.gov/)

[13] Wang Z, Benavides P T, Dunn J, Cronauer D, 2015 Development of GREET catalyst module (Lemont, IL: Argonne National Laboratory ANL/ESD- 14/12 Rev)

[14] Han J, Tao L, Wang M, 2016 Well-To-Wake Analysis of Ethanol-To-Jet and Sugar-To-Jet Pathways Biotechnology for Biofuels Accepted for publication.

[15] Idaho National Laboratory (INL) 2014 Biomass Feedstock Supply System Design and Analysis INL/EXT-14-33227. Idaho Falls, Idaho.

[16] Alonso D M, Wettstein S G, Dumesic J A, 2012 Bimetallic catalysts for upgrading of biomass to fuels and chemicals Chemical Society Reviews 41 7965-8216

[17] Benavides PT, Dai Q, Sullivan J, Kelly J C, Dunn J, 2015 Material and Energy Flows Associated with Select Metals in GREET2: Molybdenum, Platinum, Zinc, Nickel, Silicon (Lemont IL: Argonne National Laboratory ANL/ESD-15/11)

[18] Anglo American Platinum, 2014 Sustainable Development Report. Republic of South Africa http://www.angloamerican.com/ /media/Files/A/Anglo-American-PLC-V2/report-builder2014/sdr/sdr14-interactive-version.pdf (accessed 15.04.15)

[19] Loferski PJ, 2015 Platinum-Group Metals Statistics and Information, U.S Geological Survey, February. http://minerals.usgs.gov/minerals/pubs/commodity/platinum (accessed 13.04.15)

[20] Robb L, 2005 Introduction to Ore-forming Processes Blackwell Oxford UK

[21] Renner H, 1992, Platinum Group Metals and Compounds Vol. A21 in Ullmann's Encyclopedia of Industrial Chemistry $5^{\text {th }}$ ed (Weinheim Germany: B. Elvers S. Hawkins, and G. Schulz)

[22] IEA International Energy Agency, 2012, South Africa: Electricity and Heat. http://www.iea.org/statistics/ statisticssearch/report/year=2012\&country=SOUTHAFRIC\&product=ElectricityandHeat (accessed 15.05.15)

[23] ElA-Energy Information Administration, 2015, Monthly Energy Review-Electricity, March http://www.eia.gov/totalenergy/data/monthly/ (accessed 20.05.15)

[24] Fthenakis MVH, Chul Kim, Wang W, 2007 Life Cycle Inventory Analysis in the Production of Metals Used in Photovoltaics (Upton NY: Brookhaven National Laboratory, Energy Sciences and Technology Department)

[25] Thompson Creek Mining Company, 2013 Air permit application to convert tier II operating permit a permit to construct submitted to Idaho Division of Environmental Quality- Air Quality Division, ID.

[26] Kumar CG, 2002 Chemical Metallurgy: Principles and Practice (Mumbai, India: Wiley-VCH) 
[27] U.S. Environmental Protection Agency EPA, 1994, Molybdenum, Ferromolybdenum, and Ammonium Molybdate http://www.epa.gov/wastes/nonhaz/industrial/special/mineral/pdfs/part7.pdf (accessed 22.04.15)

[28] Climax Molybdenum Company, 2013 Air Quality Operating Permit-Title V Operating Permit, lowa Department of Natural Resources, lowa.

[29] Lloyd L, 2011 Handbook of Industrial Catalysts (New York, NY: Springer)

[30] Bertolacini R, 2014 Personal communication from D.C. Cronauer Argonne National Laboratory to Bertolacini R Argonne National Laboratory May 14

[31] Pomarède V, 2014 Recycling of spent oil catalysts: Gulf Chemical and Metallurgical Corporation process for metals recovery (Dallas, TX: $247^{\text {th }}$ ACS Nat. Mtg. and Exposition March 19)

[32] Kim C H, Woo S I, Jeon S H, 2009 Recovery of platinum group metals from recycled automotive catalytic converters by carbochlorination Ind. Eng. Chem. Res. 39 1185-1192

[33] Aberasturi DJ, Pinedo R, Larramendi IR, Larramendi JIR, Rojo T, 2011 Recovery by hydrometallurgical extraction of the platinum-group metals from car catalytic converters Minerals Engineering 24 505-513

[34] Barakat M A, Mahmound M H H, 2004 Recovery of platinum from spent catalyst Hydrometallurgy 72 179-184

[35] Appell H R, 1958 Recovery of Platinum from Alumina Base Platinum Catalyst U.S. Patent 2830877A (issued 15 April)

[36] Bernardis F L, Grant R A, Sherrington D C, 2005 A review of methods of separation of the platinumgroup metals through their chloro-complexes Reactive \& Functional Polymers 65 205-217

[37] Benson M, Bennett C R, Harry J E, Patel M K, Cross M, 2000 he recovery mechanism of platinum group metals from catalytic converters in spent automotive exhaust systems Resources Conservation and Recycling 31 1-7

[38] Furimsky E, Massoth FE, 1999 Deactivation of hydroprocessing catalysts Catalysis Today 52381 495

[39] Ravenelle RM, 2011 Heterogeneous catalysts in aqueous phase reforming environments: an investigation of material stability Thesis: Dissertation for Georgia Inst. Tech.

[40] Jothimurugesan K, 2016 Stable support for Fischer-Tropsch catalyst Patent US9233358 B1

[41] Eijsbouts S, Battiston AA, Van Leerdam GC, 2008 Life cycle of hydroprocessing catalysts and total catalyst management Catalysis Today 130361 - 373

[42] Dufresne P, 2007 Hydroprocessing catalysts regeneration and recycling Applied Catalysis A: General $32267-756$ 